\title{
A IMPLEMENTAÇÃO DA POLÍTICA NACIONAL DE EDUCAÇÃO ESPECIAL NA PERSPECTIVA DA EDUCAÇÃO INCLUSIVA EM REDES MUNICIPAIS DE ENSINO EM PONTA GROSSA E CURITIBA, NO ESTADO DO PARANÁ
}

\section{The implementation of the National Policy of Special Education in the Inclusive Education Perspective in municipal schools in Ponta Grossa and Curitiba, Paraná State}

Amanda Sousa Batista do Nascimento -Universidade Nove de Julho (UNINOVE)/Brasil Tatiana Zanini da Silva Patiño - Universidade Nove de Julho (UNINOVE)/Brasil

RESUMO: O presente artigo tem por objetivo principal discutir a implementação da Política Nacional de Educação Especial na Perspectiva da Educação Inclusiva em redes municipais de ensino em Ponta Grossa e Curitiba, no estado do Paraná. Trata-se de uma revisão de literatura, com ênfase na análise de dois estudos acadêmicos acerca do processo de implementação desta política em redes municipais de ensino brasileiras: uma em Ponta Grossa e outra em Curitiba, no estado do Paraná. Para analisar a implementação da Política Nacional de Educação Especial na Perspectiva da Educação Inclusiva nesses municípios, este artigo utiliza-se das pesquisas realizadas por Joslin (2014) e Kowalski (2011) que apresentam o cenário no qual as políticas educacionais inclusivas têm se consolidado nas redes de ensino supracitadas, considerando os aspectos facilitadores para sua implementação e verificando quais deles são efetivamente encontrados no processo. Para tanto, faz-se necessário o debate sobre significado da inclusão, de políticas públicas inclusivas e de marcos históricos da Educação Inclusiva no Brasil.

Palavras-chave: Educação. Inclusão. Direito. Políticas Educacionais Inclusivas.

ABSTRACT: This article aims to discuss the implementation of the National Policy of Special Education in the Inclusive Education Perspective in municipal education networks in Ponta Grossa and Curitiba, Paraná state. This is a literature review, with emphasis on the analysis of two academic studies on the process of implementation of this policy in municipal schools at two Brazilian cities: in Ponta Grossa and in Curitiba, theboth in Paraná State. To analyze the implementation of the National Policy of Special Education in the Inclusive Education Perspective in the cities mentioned above, this article uses the research conducted by Joslin (2014) and Kowalski (2011) that presents the scenario in which inclusive educational policies have been consolidated in the aforementioned education networks, considering the facilitating aspects for its implementation and verifying which ones are effectively found in the process. Therefore, it is necessary to debate the meaning of inclusion, inclusive public policies and historical milestones of Inclusive Education in Brasil.

Keywords: Law. Education. Inclusion. Inclusive Educational Policies.

\section{INTRODUÇÃ̃O}

As discussões que permeiam a educação e a sua garantia por direito estabelecido não são recentes. Elas estão presentes nos diferentes movimentos sociais ao longo da história da humanidade e continuam sendo debatidas até os dias atuais. Muitos 
A implementação da Política Nacional de Educação Especial na Perspectiva da Educação Inclusiva em redes municipais de ensino em Ponta Grossa e Curitiba, no Estado do Paraná

documentos validaram esse percurso histórico, dentre eles, a própria Constituição da República Federativa do Brasil, que adota como princípio em seu artigo 205:

A educação, direito de todos e dever do Estado e da família, será promovida e incentivada com a colaboração da sociedade, visando ao pleno desenvolvimento da pessoa, seu preparo para o exercício da cidadania e sua qualificação para o trabalho (BRASIL, 1988).

A Constituição (1988) também orienta nos artigos 208 e 227, especificamente sobre a pessoa com deficiência, que o Atendimento Educacional Especializado (AEE) para os alunos com deficiência seja oferecido, preferencialmente, na rede regular de ensino. Destaca que deve haver a criação de programas preventivos, que favoreçam a convivência, o treinamento para o trabalho e o acesso aos serviços coletivos, eliminando qualquer tipo de barreiras arquitetônicas ou preconceituosas.

No que diz respeito à educação especial, a historicidade das Políticas Públicas Inclusivas no Brasil percorreu um longo trajeto de idas e vindas, até chegar na atual Política Nacional de Educação Especial na Perspectiva da Educação Inclusiva que, mesmo sendo um documento norteador e não uma política de Estado, foi adotada em âmbito nacional como embasamento para a articulação de ações educacionais para a garantia de acesso e permanência de estudantes com deficiência nas salas de aula regulares.

[...] a "Política Nacional de Educação Especial na Perspectiva da Educação Inclusiva" (BRASIL, 2008), não tem o mesmo caráter fático, mas pode ou não ser seguida, pois se trata de uma proposição de governo e não de Estado. Tanto é assim que não depende de aprovação das câmaras institucionais, como o Poder Legislativo ou o Conselho Nacional de Educação, bem como não tem poder sobre as políticas das unidades federadas e dos municípios, servindo como documento norteador, mas sem o caráter fático da legislação (BUENO, 2011, p.11).

A Política Nacional de Educação Especial na Perspectiva da Educação Inclusiva (MEC, 2008), com validade em todo o território brasileiro, completa 11 anos de sua criação, e continua a orientar os programas e ações nessa área para promover o acesso e a permanência de alunos com deficiência, transtornos globais do desenvolvimento e altas habilidades/superdotação, público alvo da Educação Especial, no ensino regular, ampliando a oferta do atendimento educacional especializado, rompendo com o modelo 
de integração em escolas e classes especiais a fim de superar a segregação e exclusão educacional e social das pessoas com deficiência.

Nesse sentido, este estudo apresenta uma revisão de literatura com ênfase na análise de dois estudos acadêmicos acerca do processo de implementação dessa política em redes municipais de ensino brasileiras: em Ponta Grossa e Curitiba, no estado do Paraná, nos quais as pesquisadoras Joslin (2014) e Kowalski (2011) apresentam o cenário no qual as políticas educacionais inclusivas têm se consolidado nas redes de ensino supracitadas, considerando os aspectos facilitadores para sua implementação e verificando quais deles são efetivamente encontrados no processo.

Aranha (1995) evidencia que, se alijando o deficiente da integração social, este perde em desenvolvimento enquanto a sociedade perde por não ter a oportunidade e a possibilidade de aprender com uma significativa parcela de seus elementos constitutivos, representados pelo "diferentes" segregados. Ainda segundo Aranha (2001), a oferta de oportunidades equiparadas não é sinônimo de normalização, ou seja, a tentativa de tornar as pessoas com deficiência o mais próximo das pessoas ditas "normais". O processo de desqualificação é diretamente ligado ao sistema capitalista que considera o deficiente um peso à sociedade quando não produz e não contribui com o aumento do capital.

Não adianta prover igualdade de oportunidades, se a sociedade não garantir o acesso da pessoa com deficiência a essas oportunidades. Muitos são os suportes necessários e possíveis de imediato. Outros demandam maior planejamento a médio e longo prazo, caso se pretenda alcançar uma sociedade justa e democrática (ARANHA, 2001, p. 21).

Por isso, a Política Nacional de Educação Especial na Perspectiva da Educação Inclusiva é um projeto que visa discutir, elaborar, planejar, implementar e avaliar um projeto educativo específico para as pessoas com deficiência, mas sem negar a esses educandos as mesmas condições e oportunidades equiparadas de acesso, que os demais alunos têm. Segundo Cury (2005), as políticas inclusivas:

[...], podem ser entendidas como estratégias voltadas para a universalização de direitos civis, políticos e sociais. Desse modo, as políticas públicas includentes corrigem as fragilidades de uma universalidade focalizada em todo e cada indivíduo e que, em uma sociedade de classes, apresenta graus consideráveis de desigualdades. Neste sentido, "as políticas inclusivas trabalham com os conceitos de igualdade e de universalização, tendo em vista a redução da desigualdade social" (CURY, 2005, p.14-15). 
A implementação da Política Nacional de Educação Especial na Perspectiva da Educação Inclusiva em redes municipais de ensino em Ponta Grossa e Curitiba, no Estado do Paraná

Dessa maneira, pode-se observar que a ação do Estado sofreu muitas modificações ao longo dos anos, visto que há um histórico de ações excludentes e preconceituosas que se modificou, paulatinamente, para um olhar mais criterioso com a proteção e o desenvolvimento social. Tais mudanças tiveram como marco de início a Constituição de 1988, por assegurar a garantia de direitos e deveres de e para todos os cidadãos da República Federativa do Brasil.

No que concerne ao fato da obrigatoriedade em incluir os alunos com deficiência, há que se considerar os diversos desafios encontrados no cotidiano da sala de aula regular pelos profissionais de educação decorrentes do ingresso de um número cada vez maior de pessoas nessa situação no sistema. O problema reside no modelo educacional vigente sobre o qual cabe refletir e avaliar se ele realmente respeita as individualidades dos envolvidos e se a autonomia e a discricionariedade que esse sistema apregoa permitem que estes profissionais da educação se sintam seguros em sua atuação ou se são apenas subterfúgios do poder público para eximir-se da responsabilidade quanto à formação necessária e continuada para que desenvolvam com maestria o seu fazer pedagógico.

Não se pode negar que o número de alunos com deficiência inserido no ensino regular cresceu de forma gigantesca nos últimos 10 anos. Dados oficiais apontam que, no "que se refere à inclusão em classes comuns do ensino regular, verifica-se um crescimento de $640 \%$ passando de 43923 alunos em 1998 para 325.316 em 2006" (BRASIL, 2008, item III).

Na década de 1930, com o início do processo de industrialização do país, acontecimentos políticos, econômicos e sociais marcam a sociedade brasileira e deixam fortes impressões nas formas de organização do ensino no Brasil. Emerge nesse momento um modelo de educação homogeneizadora, que ainda resiste atualmente, mesmo diante das novas concepções de escola, ensino, professor e estudante.

$\mathrm{Na}$ realidade brasileira, os registros históricos e legais informam que o atendimento das pessoas com deficiência inicia-se na época imperial, com a criação de instituições específicas para atendimento de pessoas cegas e surdas: o Imperial Instituto dos Meninos Cegos, em 1854 e o Instituto dos Surdos Mudos, em 1857. Hoje, essas instituições possuem outras denominações: Instituto Benjamin Constant - IBC e Instituto Nacional da Educação dos Surdos - INES, ambos localizados no Rio de Janeiro. Já no século XX, são fundadas outras instituições: em 1926, o Instituto Pestalozzi para 
atendimento de pessoas com Deficiência Mental, hoje denominada como Deficiência Intelectual, de acordo com o DSM-V; em 1954, surge a primeira Associação de Pais e Amigos dos Excepcionais; em 1945, surge o primeiro Atendimento Educacional Especializado (A.E.E.) às pessoas com superdotação, oferecido por Helena Antipoff, na Sociedade Pestalozzi.

A primeira Lei de Diretrizes e Bases de 1961 - LDB/1961, em seu artigo 89, apontava que a educação dos alunos com deficiência deveria, "no que for possível, enquadrar-se no sistema geral de educação, a fim de integrá-los na comunidade" (BRASIL, 1961, on-line). Também continuava ratificando a existência e o financiamento das instituições especializadas.

Em 1971, a LDB passou por uma revisão, instituindo-se a LDB nº. 5.692/71. No que diz respeito à Educação Especial, em seu artigo $9^{\circ}$, define que "os alunos que apresentem deficiências físicas ou mentais, os que se encontrem em atraso considerável quanto à idade regular de matrícula e os superdotados deverão receber tratamento especial [...]" (BRASIL, 1971, on-line).

Kassar (2011) aponta que, mediante essa nova realidade, constata-se um aumento considerável do número de salas especiais nos diversos municípios do Brasil, por ponderarem o que a legislação compreendia por aluno com deficiência.

As instituições específicas para o atendimento educacional de pessoas com deficiência, as chamadas escolas especiais, ainda existem atualmente, atendem à especificidade que o processo educacional do deficiente exige, mas, em contrapartida, a justificativa para o seu surgimento e para que muitos profissionais da área da educação defendam este modelo de escola segregador em si mesmo, é algo a se discutir. Estas instituições foram criadas para diminuir as desvantagens, mas "o período da passagem do momento da exclusão para o momento da inclusão está se transformando num modo de vida, está se tornando mais do que um período transitório" (MARTINS, 1997, p. 33).

Um marco fundamental na mudança de paradigma relacionado ao acesso das pessoas com deficiência à educação é a discussão feita na Conferência Mundial de Educação para Todos, em Jomtien (Tailândia), com financiamento da Organização das Nações Unidas para a Educação, a Ciência e a Cultura (UNESCO), Fundo das Nações Unidas para a Infância (UNICEF), Programa das Nações Unidas para o Desenvolvimento (PNUD) e pelo Banco Mundial, considerada um dos principais documentos mundiais sobre educação, equiparada com a Declaração de Salamanca (1994), que é marco 
A implementação da Política Nacional de Educação Especial na Perspectiva da Educação Inclusiva em redes municipais de ensino em Ponta Grossa e Curitiba, no Estado do Paraná

histórico para a educação de pessoas com deficiência, assegurando que até mesmo pessoas com deficiências severas tenham seus direitos assegurados nessa área.

Nos últimos dez anos de Política Nacional de Educação Especial na Perspectiva da Educação Inclusiva, muitas mudanças ocorreram no sentido de implementação de ações efetivas nas escolas públicas brasileiras para garantir o acesso e permanência dos alunos com deficiências nas salas de aula regulares, implantação de Salas de Recursos multifuncionais para complementar o processo de ensino e aprendizagem dos educandos público-alvo da Educação Especial, investimento na formação inicial e continuada de professores acerca das temáticas inerentes à Educação Inclusiva.

Muitas dessas mudanças ainda vêm acontecendo pelas novas legislações. No entanto, Skliar (2001) ressalta que apenas a legislação não modificará a estrutura das relações que compõe o contexto escolar, concluindo que a educação brasileira não tem sofrido mudanças substanciais no contexto que se refere à educação inclusiva.

[...] de um lado, a alteridade, na escola inclusiva, permanece quase sempre no plano textual/ curricular: fala-se de ele, ele é respeitado, ele é urna temática a ser abordada; porém não é sujeito da pedagogia. Os professores e alunos aprendem dele, sobre ele, ao redor dele; fazem-se mais solidários, mais sensíveis e mais tolerantes ao problema da alteridade. De outro lado, a escola inclusiva, parece mais um novo enfoque da educação especial e não da educação no geral (SKLIAR, 2001, p. 17).

Somente as leis não favorecerão uma mudança nas práticas pedagógicas docentes, sendo esse o grande desafio do ensino regular. Faltam reflexões acerca das práticas pedagógicas que considerem a singularidade de cada sujeito nas Unidades Escolares. As discussões pedagógicas nesses espaços, regra geral, oportunizam muito mais a escuta das dificuldades trazidas pelo professor do que o estudo, a fim de discutir, aprofundar teoricamente e qualificar a prática já existente. Aprofundar essas discussões aproxima teoria e prática, o que culmina na inclusão efetiva do sujeito ao meio social em que se insere e justifica a necessidade de discussão do tema proposto por este artigo.

\section{MATERIAIS E MÉTODO}

A metodologia, segundo Rapimán (2015), deve ser compreendida como a lógica dos princípios gerais que orientam as etapas de uma investigação sistemática para produzir o conhecimento. Consistem no conjunto de procedimentos, estratégias e meios técnicos utilizados 
em uma investigação. Em nosso estudo, cuja abordagem é qualitativa, para amparar as discussões acerca do tema proposto neste artigo, utilizamos como procedimento a revisão de literatura existente sobre a implementação da Política Nacional de Educação Especial na Perspectiva da Educação Inclusiva (2008), a partir da busca em banco de teses e dissertações da CAPES, em bases de dados de artigos como Scielo (Scientific Eletronic Library Online), Redalyc e Google Acadêmico, com os seguintes descritores: políticas educacionais inclusivas, educação inclusiva.

A referida busca ativa nos bancos de dados de pesquisas acadêmicas resultou na escolha de duas dissertações de mestrado: “A Política de Inclusão em escolas da Rede Municipal de Ponta Grossa-PR" da pesquisadora Melina de Fátima Andrade Joslin e "Políticas Públicas para a Educação Inclusiva: Análise das Diretrizes Curriculares no Município de Curitiba (2000-2009)” da pesquisadora Beatriz Micaloski Kowalski.

Os dois estudos acima citados se destacaram durante a revisão de literatura por serem correlatos à implementação de Políticas Educacionais Inclusivas, com ênfase no recorte histórico utilizado pelas pesquisadoras, no qual se compreende o processo de implementação da Política Nacional de Educação Especial na Perspectiva da Educação Inclusiva(2008), documento no qual sustentamos nossa discussão, considerando a sua relevância para a inclusão escolar de estudantes brasileiros com deficiência.

\section{EDUCAÇÃO ESPECIAL NA PERSPECTIVA DA EDUCAÇÃO INCLUSIVA: REDES MUNICIPAIS DE ENSINO EM PONTA GROSSA E CURITIBA}

As pesquisas de Joslin (2012) e Kowalski (2011) possibilitam verificar como se deu o processo de implementação da Política Nacional de Educação Especial na Perspectiva da Educação Inclusiva em dois municípios brasileiros (Ponta Grossa e Curitiba). Afirmam que a legislação vigente acerca desta temática possui âmbito nacional, sendo que, os municípios e estados têm autonomia na criação de políticas públicas locais que atendam às demandas da política nacional, conforme a realidade que possuem.

Joslin (2012) apresenta como a política de inclusão de alunos com necessidades especiais era colocada em prática nas Unidades Escolares da Rede Municipal de Ensino de Ponta Grossa - Paraná, tendo como recorte histórico o ano de 2010. As ações foram pautadas na política nacional, que assegura aos municípios a autonomia de adotá-la e implementá-la. A pesquisadora explicita que no município de Ponta Grossa - PR, a Secretaria de Educação, a partir de 2005, escolheu não elaborar uma proposta própria de 
A implementação da Política Nacional de Educação Especial na Perspectiva da Educação Inclusiva em redes municipais de ensino em Ponta Grossa e Curitiba, no Estado do Paraná

política de educação inclusiva, e sim optou por incorporar as propostas do Governo Federal.

Neste contexto, Joslin (2014) enaltece que o papel do Estado representado pela Secretaria Municipal de Ponta Grossa vai muito além da formulação e regulação de políticas, pois os resultados da pesquisa de campo evidenciaram que a criação de estratégias de apoio aos profissionais que atuam diretamente com este público-alvo é algo elementar para que a política seja colocada em ação de maneira mais efetiva.

A dissertação de mestrado de Kowalski (2011) apresenta dados de pesquisa que estudou as políticas educacionais brasileiras, com foco na Educação Inclusiva, pautada nas declarações internacionais e a influência delas no processo de inclusão educacional brasileiro, tendo como lócus de pesquisa o município de Curitiba, com a análise de suas Diretrizes Curriculares nos anos de 2000 a 2009.

As análises da autora permitem a percepção de como as relações políticas, sociais e econômicas estão estabelecidas e influenciam na elaboração de políticas públicas que fundamentam a Educação Inclusiva da pessoa com deficiência tendo como recorte histórico o período entre 1990 e 2010. Kowalski (2011) apresenta abordagem crítica da discussão da Educação Inclusiva no contexto no neoliberalismo. Nesse sentido, com relação à inclusão educacional, a autora enfatiza que as políticas educacionais de cunho neoliberal, com a proposta de educação inclusiva sob o slogan "Educação para Todos" (UNESCO, 1990), “ao priorizar a ordem capital subvertem as suas proposições e, afinal, restringem quantitativa e qualitativamente o acesso dos expropriados aos bens culturais e materiais" (KOWALSKI, 2011, p.26).

Entre diversos dados históricos que Kowalski (2011) elucida em sua pesquisa acerca de como se deu o processo de inclusão de pessoas com deficiência nas escolas brasileiras, a autora explicita que, em 1986, foi criada a Secretaria de Educação Especial (SESPE) cujo objetivo era organizar e coordenar os trabalhos e pesquisas realizados acerca da Educação Especial. A SESPE foi extinta em 1990, dando lugar para o Departamento de Educação Supletiva e Especial (DESE) que fazia parte da Secretaria Nacional de Educação Básica (SENEB).

Durante o governo Collor (1992), com uma reorganização do Ministério da Educação e Cultura, Santos (2006) elucida que ressurgiu a Secretaria de Estado de Educação Básica (SEESP) com a premissa de abrir possibilidades para integrar os alunos 
com deficiência, "coexistiria também uma atitude de marginalização por parte dos sistemas educacionais, que não ofereciam as condições necessárias para que os 'alunos com deficiência' alcançassem o sucesso na escola regular" (SANTOS, 2006, p.30).

Segundo Kowalski (2011) a década de 1990 foi demarcada por profundas discussões e modificações provenientes dos processos de globalização, da ascensão do neoliberalismo, a reconfiguração do sistema produtivo comandado pelo capitalismo em expansão e as questões advindas do mercado de trabalho. Assim sendo, a temática da inclusão surge cada vez mais nas discussões sociais e nos relatórios anuais dos governos, inclusive influenciados pelos acordos mundiais elaborados, financiados e repercutidos pelas agências multilaterais como o Banco Mundial, Cepal, Unesco, etc.

Nessa perspectiva, as políticas públicas tornam-se mais ativas com o intuito de diminuir as desigualdades e oportunizar educação para todos e o cenário educacional passa a ser menos exclusivo. De acordo com Kowalski (2011), a formulação de leis e políticas pública voltadas para a inclusão e garantidoras de direitos das pessoas com deficiência no Brasil se deram a partir de um contexto mundial, visto que, desde 1980, ideias de leis e diretrizes para a Educação Especial passaram a ser discutidas.

Sob a égide desses ideais, as Diretrizes Curriculares nos anos de 2000 a 2009 foram construídas, mas, conforme analisadas pela pesquisadora, nem sempre atendiam às necessidades educacionais dos alunos com deficiência do município de Curitiba, ou às demandas primordiais de garantia de acesso e permanência. Tal cenário começou a ganhar contornos diferentes em 2006, quando o município incorporou a Educação Inclusiva em suas Diretrizes Curriculares, que logo foram validados com a implementação da Política Nacional de Educação Especial na Perspectiva da Educação Inclusiva (2008).

A referida autora destaca que os anos 1990 são cruciais nas discussões acerca da construção de uma escola inclusiva, pois esta temática foi acentuada de forma significativa com o Movimento Educação para Todos, cuja abrangência é internacional, por meio de políticas internacionais com o apoio da UNESCO, almejando o acesso à escolarização para todos (KOWALSKI, 2011, p. 49).

Um dos documentos mais discutidos no âmbito da Educação Inclusiva é a Declaração de Salamanca, que "deu à escola uma gama de atribuições no combate a atos discriminatórios", de modo a contribuir com a existência de uma sociedade inclusiva que versa palavras do mundo econômico como eficiência e eficácia. (KOWALSKI, 2011, p. 50-51)

Educação, Psicologia e Interfaces, Volume 4, Número 1, p. 20-35, Janeiro/Março, 2020. 
A implementação da Política Nacional de Educação Especial na Perspectiva da Educação Inclusiva em redes municipais de ensino em Ponta Grossa e Curitiba, no Estado do Paraná

Vale ressaltar que o Brasil fez a opção em construir um ensino inclusivo quando incorporou as recomendações instituídas na Assembleia realizada em Salamanca, na Espanha, no ano de 1994. Mesmo não tendo representação no evento por questões burocráticas do próprio Ministério da Educação, o país foi um dos signatários da denominada como Declaração de Salamanca. Sendo assim, procurou não medir esforços para realizar políticas públicas que garantissem a qualificação no sistema de ensino, a fim de incluir todos os alunos, independentemente de suas especificidades ou dificuldades individuais e buscou diferentes estratégias e intervenções precoces para os alunos da educação inclusiva. Aos professores, caberia formação e treinamento em serviço. A Declaração de Salamanca foi um grande marco internacional para a educação, pois favoreceu a criação de diretrizes norteadoras para a formulação e reestruturação de políticas públicas nos sistemas educacionais de vários países. Nesta Assembleia, os diversos países puderam discutir e ampliar o conceito de necessidades educacionais especiais, pois o objetivo estava em incluir qualquer aluno que não estivesse se beneficiando do contexto escolar, sendo deficiente ou não.

[...] reafirmando as Declarações de Jomtien (1990) e Salamanca (1994), o governo brasileiro atendeu às orientações dos organismos internacionais com vistas, não somente a erradicar o analfabetismo, como a buscar a educação para todos, conforme compromisso assumido nas referidas conferências (KOWALSKI, 2011, p.63).

Nesse contexto, é importante evidenciar o papel das agências multilaterais, como a Comissão Econômica para a América Latina (CEPAL), que publicou na década de 1960 uma série de definições de marginalidade social, como "falta de integração e participação das populações marginais nas sociedades em que vivem" e "um modo limitado e sem consistência de pertencer e de participar da estrutura geral da sociedade" (PATTO, 2008, p. 26-27).

Ao analisar os principais documentos internacionais associados ao ideal de educação inclusiva, Kowalski (2011) destaca que esse modelo inclusivo não foi uma invenção de Salamanca, mas consequência de um processo que vinha se desenvolvendo e que adquiriu repercussão a partir da Declaração de Jomtien (1990).

O marco histórico-político da Constituição de 1988 foi o ponto de partida para que algumas redes de ensino já começassem a idealizar um modelo educacional inclusivo, 
de modo a atender às demandas legais e sociais: a garantia de acesso, permanência e currículo a todos os educandos. A Educação Inclusiva no currículo básico da Rede Municipal de Ensino de Curitiba implantada em 1996, investigada por Kowalski (2011), a experiência de implantação de uma política de inclusão na rede municipal de Ponta Grossa - PR, pesquisada por Joslin (2014) são exemplos desse modelo.

Mediante os dados coletados por Joslin (2014) quanto ao percurso de inclusão em desenvolvimento na rede municipal de Ponta Grossa-PR, constatou-se que o acesso à escola nem sempre significa garantia de direito à educação, visto que dar suporte ao professor e considerar as propostas curriculares e possibilidades de acesso ao currículo por meio de tarefas diferenciadas, adaptações temporais e oferta de suporte necessário aos alunos não é uma conduta unânime nas unidades escolares, embora seja esta a indicação para promover a educação inclusiva.

Joslin (2014) constatou que entre os professores das classes regulares e os professores de apoio à inclusão há um reconhecimento de que a diversidade das classes regulares exige uma adaptação do currículo comum. Entretanto, dificuldades de viabilização são encontradas no processo. Bueno (2008) reitera esta perspectiva apontando que é necessário que o professor de sala regular e professor da educação especial tenham um tempo para discutirem as questões referentes ao trabalho colaborativa entre ambos; como no momento do horário de trabalho coletivo da escola, buscando assim, a qualidade no ensino.

A experiência de Curitiba, segundo Kowalski (2011), por meio de análise documental a partir do Currículo Básico de 1997 e das Diretrizes Curriculares de 2009, teve como foco de pesquisa a Educação Inclusiva, demonstrando que a educação foi vista como prioridade política, compreendendo-a como:

[...] processo de formação continuada dos cidadãos, a partir dos saberes historicamente situados e de práticas educacionais pautadas na cooperação, na colaboração, no respeito mútuo, no respeito à diversidade étnico- racial e cultural, na inclusão irrestrita, nos valores éticos e na preservação da vida (DIRETRIZES CURRICULARES, 2006-2009, v.1 apud KOWALSKI, 2011, p. 94).

Kowalski (2011) explicita que em Curitiba foi criada em 2005 a Coordenadoria de Atendimento às Necessidades Especiais (CANE) com o objetivo de coordenar os processos referentes à orientação e ao atendimento às necessidades educacionais especiais, corroborando a Educação Inclusiva. A referida autora chegou à conclusão em 
A implementação da Política Nacional de Educação Especial na Perspectiva da Educação Inclusiva em redes municipais de ensino em Ponta Grossa e Curitiba, no Estado do Paraná

suas pesquisas que o comprometimento com a Educação para Todos no município de Curitiba se concretiza a partir da ação de manter a Escola de Educação Especial, na contramão da maioria dos Estados brasileiros, pois

[...] diante da diversidade dos educandos e de importantes conquistas do direito à educação básica, foi criada, na Secretaria Municipal de Educação de Curitiba, a Coordenadoria de Atendimento às Necessidades Especiais, que tem como finalidade coordenar os processos referentes à orientação e ao atendimento das necessidades educacionais especiais de estudantes das Instituições de Educação e Ensino Públicas Municipais (KOWALSKI, 2011, p.105).

Em suma, mediante os resultados de sua pesquisa, Joslin (2014) conclui que por meio das condições do contexto onde a política é colocada em prática e das interpretações realizadas pelos agentes escolares, uma escola pode estar mais próxima ou mais distante do ideal de educação inclusiva. Ou seja, a inclusão efetiva demanda que todos os alunos sejam recebidos com igualdade no seu processo de escolarização: igualdade no acesso, na permanência, no tratamento e no encaminhamento às próximas etapas de seu processo de escolarização. Mittler (2003) corrobora esse pensamento ao salientar a importância das discussões que ocorrem no contexto escolar, para o processo inclusivo:

Inclusão e exclusão começam na sala de aula. Não importa o quão comprometido um governo possa ser com relação à inclusão; são as experiências cotidianas das crianças nas salas de aulas que definem a qualidade de sua participação e a gama total de experiências de aprendizagem oferecidas em uma escola. As formas através das quais as escolas promovem a inclusão e previnem a exclusão constituem o cerne da qualidade de viver e aprender experimentado por todas as crianças (MITTLER, 2003, p.140).

Kowalski (2011) conclui que todas as iniciativas tomadas no município de Curitiba para implantar um modelo de educação inclusiva, não a torna infalível, contudo, demonstra comprometimento, aponta para aspectos a serem melhorados e relembra que não basta a garantia de matrícula de todos os estudantes para que uma rede de ensino seja considerada totalmente inclusiva.

O desafio está muito além do acesso à escola desses alunos; considera-se aqui a importância da escola e dos profissionais que compõem este espaço de repensarem suas práticas sob a perspectiva inclusiva, visto que os profissionais estão inseridos numa sociedade historicamente excludente. Matiskei (2004, p.187) aponta que: 
[...] o leque da exclusão social é tão grande quanto são os mecanismos de imposição de padrões de normalidade aos quais a humanidade esteve submetida historicamente, que preconizam modelos estéticos, de inteligência, de linguagem, de condição econômica e cultural, com que devemos nos conformar, sob o risco de engrossarmos as fileiras dos excluídos socialmente. Inclusão e exclusão são facetas de uma mesma realidade: discutir mecanismos para viabilizar a inclusão social, econômica, digital, cultural ou escolar significa admitir a lógica intrinsecamente excludente presente nos atuais modos de organização e produção social que se querem modificar.

A sociedade no qual esses sujeitos (alunos e profissionais) estão inseridos evidencia no indivíduo a competitividade, a individualidade e padrões que são aceitos por esta sociedade. Caberá a escola, contestar esses padrões, essa cristalização que se criou historicamente (de que todos têm de serem iguais e terem os mesmos desenvolvimentos), oportunizando espaços de problematização que superem essas práticas excludentes.

\section{CONSIDERAÇÕES FINAIS}

A problematização acerca da concepção e evolução do conceito de inclusão, o seu contexto histórico e o teórico pautaram a discussão no presente artigo e são extremamente importantes quando se trata da educação de pessoas com deficiência. Com o passar dos anos, as políticas educacionais inclusivas em âmbito nacional foram se fortalecendo, o que reverberou também nas esferas estaduais e municipais, como elucidado neste artigo por meio da exemplificação da realidade da educação pública municipal de dois municípios no Estado de Curitiba (PR). Com o respaldo legal de documentos nacionais e internacionais, a Política Nacional de Educação Especial na Perspectiva da Educação Inclusiva (2008) foi delineada, implementada e avaliada desde a sua proposição até à prática real nas escolas.

Os estudos e pesquisas desenvolvidos por Kowalski (2011) e Joslin (2014) contribuem para compreender todo o movimento educacional em prol de uma educação para todos, a partir do marco regulatório da Constituição de 88, em esferas municipais exemplificando quais as ações desenvolvidas em diferentes redes de ensino para implantar políticas educacionais inclusivas e para constatar qual o alcance da Política Nacional de Educação Inclusiva no âmbito da prática, considerando seus aspectos positivos e suas limitações para promover o acesso e permanência dos educandos com deficiência nas salas de aula regulares brasileiras, assegurando o seu direito à educação com as condições necessárias para promover o processo de ensino e aprendizagem.

Educação, Psicologia e Interfaces, Volume 4, Número 1, p. 20-35, Janeiro/Março, 2020. 
A implementação da Política Nacional de Educação Especial na Perspectiva da Educação Inclusiva em redes municipais de ensino em Ponta Grossa e Curitiba, no Estado do Paraná

\section{REFERÊNCIAS BIBLIOGRÁFICAS}

ARANHA, Maria Lúcia de Arruda. História da Educação. São Paulo: Moderna, 1989.

ARANHA. Maria Salete Fábio. Integração social do deficiente: análise conceitual e metodológica. Temas em Psicologia, Universidade Estadual Paulista, Bauru, n², 1995 , p. 63-70.

ARANHA. Maria Salete Fábio. Paradigmas da relação da sociedade com a pessoa com deficiência. Revista do Ministério Público do Trabalho, Ano XI, n²1, março, 2001, p.1-24.

BRASIL. Presidência da República. Constituição da República Federativa do Brasil de 1988. Disponível em: http://www.planalto.gov.br. Acesso em: set. 2009.

BRASIL. Convenção sobre os Direitos das Pessoas com Deficiência. Brasília: Secretaria de Direitos Humanos, 2010.

BRASIL. Presidência da República. Lei de Diretrizes e Bases da Educação Nacional. Lei $\mathrm{n}^{\circ} 5.692$ de 11 de agosto de 1971. Disponível em:

http://www.smec.salvador.ba.gov.br. Acesso em: maio. 2017.

BRASIL. Presidência da República. Lei de Diretrizes e Bases da Educação Nacional. Lei no 9.394 de 20 de dezembro de 1996. Diário Oficial da União de 23 de dezembro de 1996. Disponível em: http://www.planalto.gov.br. Acesso em: maio. 2017.

BRASIL.

Ministério da Educação. Secretaria de Educação Especial. Política Nacional de Educação Especial na Perspectiva da Educação Inclusiva. Brasília: MEC/SEESP, 20 08 .

BUENO, José Geraldo Silveira. As políticas de inclusão escolar: uma prerrogativa da educação especial. In.: BUENO, José Geraldo Silveira et al. Deficiências da escolarização: nova perspectiva de análise. São Paulo: Junqueira \& Martins, 2008.

BUENO, José Geraldo Silveira. Educação especial brasileira: questões conceituais e de atualidade. São Paulo: EDUC, 2011.

CURY, C. R. J. Direito à Educação: direito à igualdade, direito à diferença. Cadernos de Pesquisa, São Paulo, n. 116, p. 245-262, jul. 2002.

CURY, C. R. J. Políticas inclusivas e compensatórias na educação básica. Cadernos de Pesquisa, n. 124, p. 11-32, jan./abr.2005.

CURY, C. R. J. Sistema nacional de educação: desafio para uma educação igualitária e federativa. Caderno Cedes, Campinas, v. 29, n. 105, p. 1187-1209, set.-dez. 2008. Disponível em: http://www.cedes.unicamp.br. 
DELORS, J. Educação: um tesouro a descobrir. 2ed. São Paulo: Cortez Brasília, DF: MEC/UNESCO, 2003.

FREIRE, Paulo. Pedagogia do Oprimido. $17^{\circ}$ ed. Rio de Janeiro: Paz e Terra, 1987.

MARTINS, J. de S. Exclusão e a nova desigualdade. São Paulo: Paulus, 1987.

MARTINS, José de Souza. Exclusão social e a nova desigualdade. São Paulo: Paulus, 1997.

JOSLIN, Melina de Fátima Andrade. A Política de Inclusão em questão: uma análise em escolas da rede municipal de ensino de Ponta Grossa-PR. Dissertação de Mestrado. Universidade Estadual de Ponta Grossa, Ponta Grossa, PR, 2012.

JOSLIN, Melina de Fátima Andrade. A Política de Inclusão em escolas da Rede Municipal de Ponta Grossa-PR. X ANPED-SUL, Florianópolis, outubro, 2014.

KASSAR, Mônica de Carvalho Magalhães. Educação especial na perspectiva da educação inclusiva: desafios da implantação de uma política nacional. Educar em Revista, Curitiba, 2011, p. 61-79. Disponível em:

http://www.scielo.br/pdf/er/n41/05.pdf. Acesso em: 05. Set. 2019.

KOWALSKI, Beatriz Micaloski. Políticas Públicas para a Educação Inclusiva: Análise das Diretrizes Curriculares no Município de Curitiba (2000-2009). Dissertação (Mestrado) Universidade Tuiuti do Paraná, 2011.

MATISKEI, Angelina Carmela Romão Mattar. Políticas públicas de inclusão educacional: desafios e perspectivas. Educar em Revista, Curitiba, 2004, p. 185-202. Disponível em: http://educa.fcc.org.br/scielo.php?script=sci_arttext\&pid=S0104$40602004000100011 \& 1 n g=$ pt\&nrm=iso . Acesso em: 04 set. 2019.

MITTLER, Peter. Educação inclusiva: contextos sociais. Porto Alegre: Artmed, 2003.

NASCIMENTO, Amanda Sousa Batista do. A política nacional de educação especial na perspectiva da educação inclusiva: o processo de implementação na rede municipal de Santo André (2008-2016). Dissertação de Mestrado, Universidade Nove de Julho, São Paulo, 2018.

PADILHA, Anna Maria Lunardi. "Ensino Inclusivo": uma expressão incorreta. In: MARQUEZINE, Maria Cristina et al. Re'discutindo a inclusão. Londrina: ABPEE. 2009 , p. 5-20

PATTO, Maria Helena Souza. Políticas atuais de inclusão escolar: reflexão a partir de um recorte conceitual. In.: BUENO, José; MENDES, Geovana; SANTOS, Roseli. Deficiência e escolarização: novas perspectivas de análise. Araraquara, SP: Junqueira \& Marin; Brasília, DF: CAPES, 2008.

RÁPIMAN, Daniel Quilaqueo. Pesquisa Qualitativa em Educação: possibilidades de investigação em educação. In: TAVARES, Manuel. RICHARDSON, Roberto Jarry. Metodologias Qualitativas: teoria e prática. 1 ed. Curitiba: CRV, 2015. 
A implementação da Política Nacional de Educação Especial na Perspectiva da Educação Inclusiva em redes municipais de ensino em Ponta Grossa e Curitiba, no Estado do Paraná

SKLIAR, Carlos. Seis perguntas sobre a questão da inclusão ou de como acabar de uma vez por todas com as velhas - e novas - fronteiras em educação. Pró-Posições,

Campinas, v. 12, n. 2-3 (35-36), p. 11-21, jul./nov. 2001. Disponível em

https://www.fe.unicamp.br/pf-fe/publicacao/2106/3536-dossie-skliarc.pdf . Acesso em: 04. Set. 2019

UNESCO. Declaração de Salamanca e linha de ação sobre necessidades educativas especiais. Brasília: CORDE, 1994.

UNESCO. Declaração Mundial sobre Educação para Todos. Plano de ação para satisfazer as necessidades básicas de aprendizagem. Jomtien, Tailândia, 1990.

\section{Credenciais dos autores}

NASCIMENTO, Amanda Sousa Batista do. Doutoranda e Mestre em Educação pelo Programa de Pós Graduação em Educação (PPGE) da Universidade Nove de Julho (UNINOVE)-SP, Graduação em Pedagogia pela Faculdade de São Bernardo do Campo, FASB, Brasil. Professora Assessora de Educação Inclusiva na Prefeitura Municipal de Santo André. Email: amandasousabatista1987@ gmail.com

PATIÑO, Tatiana Zanini da Silva. Mestranda em Educação pela Universidade Nove de Julho (UNINOVE)/Brasil, Pós-graduação em Psicologia e Educação e Pedagogia pela Universidade do Grande ABC. Atualmente é Coordenadora na Gerência de Educação Inclusiva do município de Santo André. Email: tatizanini@yahoo.com.br

Endereço para correspondência: Amanda Sousa Batista do Nascimento. Email: amandasousabatista1987@gmail.com

Como citar este artigo (Formato ABNT): NASCIMENTO, Amanda Sousa Batista do; PATIÑO, Tatiana Zanini da Silva. A implementação da Política Nacional de Educação Especial na Perspectiva da Educação Inclusiva em redes municipais de ensino em Ponta Grossa e Curitiba, no Estado do Paraná. Educação, Psicologia e Interfaces, v. 4, n. 1, p. 20-35, 2020. DOI: https://doi.org/10.37444/issn-2594-5343.v4i1.221

Recebido: 10/10/2019.

Aceito: 12/12/2019.

Educação, Psicologia e Interfaces, Volume 4, Número 1, p. 20-35, Janeiro/Março, 2020.

ISSN: 2594-5343. DOI: https://doi.org/10.37444/issn-2594-5343.v4i1.221 